\section{Severe neurotoxicity due to Vinblastine in Hodgkin lymphoma}

DOI: $10.4103 / 2278-330 X .130492$

Dear Editor,

The treatment of Hodgkin lymphoma with Adriamycin, Bleomycin, Vinblastine, Dacarbazine (ABVD) regimen is considered as one of the most efficacious and least toxic modalities and is the standard of care today. Delays due to hematological toxicity do occur occasionally, but severe toxicity requiring treatment modifications are rare and rarer still are the incidences of neurotoxicity. A 20-year-old lady, with no known comorbidities presented to us with B symptoms and chest pain of 6 months duration. A contrast computed tomography (CT) chest showed a $10.9 \times 9.5 \times 9.2 \mathrm{~cm}$ large heterogeneously enhancing anterior mediastinal mass lesion without any focal lung lesion or any pleural effusion [Figure 1]. Trucut biopsy of the mediastinal mass showed features suggestive of Nodular Sclerosing Hodgkin lymphoma. Contrast CT of abdomen, bronchoscopy, and bone marrow examination were normal. She was diagnosed as Hodgkin lymphoma Stage IIBx and managed with three cycles of ABVD (Adriamycin $45 \mathrm{mg} /$ Bleomycin $17 \mathrm{mg} /$ Vinblastine $10 \mathrm{mg} /$ Dacarbazine $640 \mathrm{mg}$ ) based chemotherapy to which she responded well. She was a healthy young lady with a body surface area of $1.72 \mathrm{~m}^{2}$ and she did not require any growth factor supplements during these three cycles. She also denied intake of any alternative medicines. However, after two cycles she developed difficulty in walking and after third cycle developed frank bilateral foot drop. Clinically, there was no evidence of any other neurological deficit. Nerve conduction studies were suggestive of mixed sensory-motor neuropathy, predominantly axonal motor neuropathy involving the lower limbs [Figures 2 and 3]. An interim positron emission tomography (PET) sc an done showed complete metabolic response and also decrease in size of the mass. Workup for preexisting causes of neuropathy and diseases like megaloblastic anemia, diabetes mellitus, hypothyroidism, syphilis, and connective tissue disorders like rheumatoid arthritis and systemic lupus erythematosus was negative. Pending a decision on how best to modify further chemotherapy we treated her with $30 \mathrm{~Gy} / 15 \#$ of involved field radiotherapy to mediastinum.

We did an extensive literature search on incidence of foot drop or severe neurological toxicity secondary to vinblastine in ABVD therapy and were surprised to note that no significant data existed. ${ }^{[1,2]}$ The major toxicity reported with vinblastine was hematological and there were not even case reports on severe neurotoxicity. ${ }^{[1]}$ Literature also did not support the omission of vinblastine in further

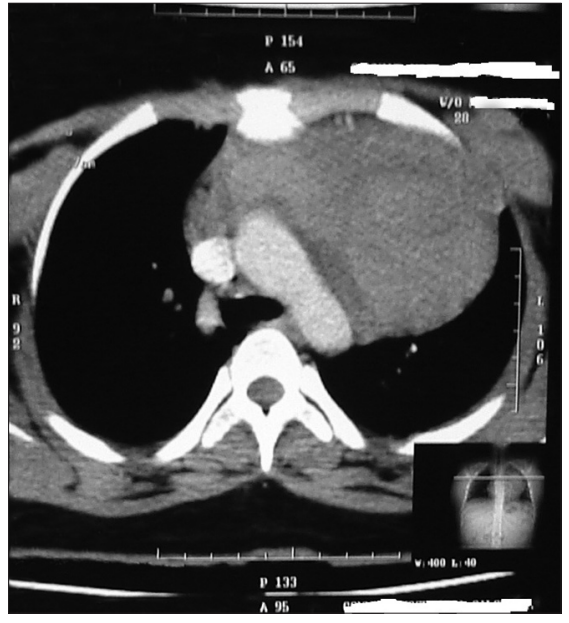

Figure 1: A 9.2 (CC) $\times 10.9$ (trans) $\times 9.5$ (AP) cm heterogeneously enhancing mass lesion in anterior-superior mediastinum

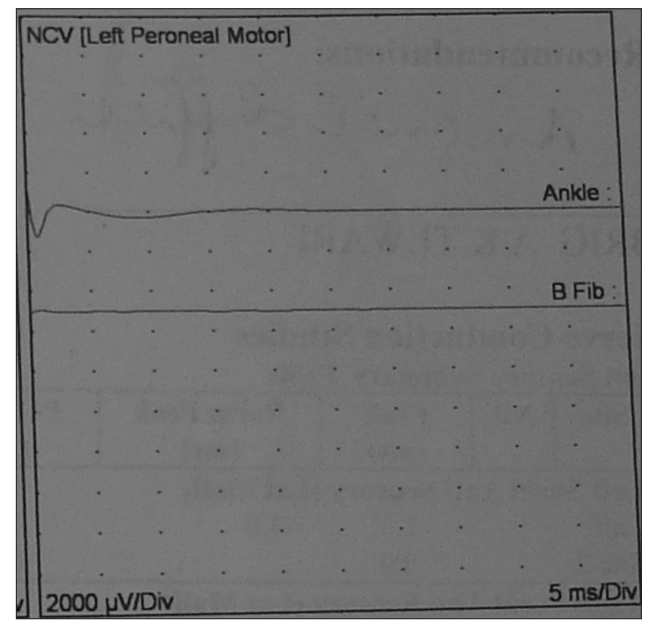

Figure 2: Left peroneal motor nerve showed no response (ankle) and no response (B Fib)

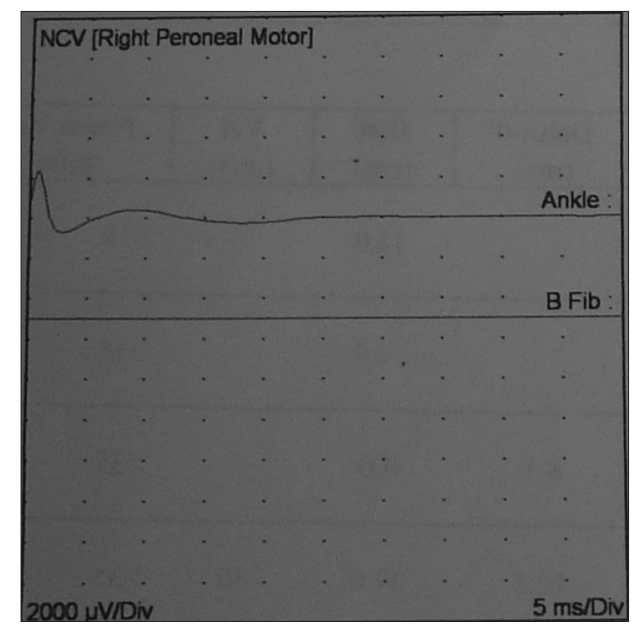

Figure 3: Right peroneal motor nerve showed no response (ankle) and no response (B Fib) 
cycles without compromising efficacy of treatment. The opinion of experts in India and Europe were sought through mails and she was finally given two cycles of Ifosfamide, Carboplatin, Etoposide (ICE) based chemotherapy as consolidation. A repeat PET scan 6 weeks after treatment confirmed complete metabolic response and residual inactive lesion of about $6 \times 7 \times 6 \mathrm{~cm}$. A repeat nerve conduction study showed persistent predominantly axonal motor neuropathy predominantly in lower limbs. Clinically, though she was able to walk unaided and able to do all activities of day-to-day living.

The rare presentation of severe neurotoxicity in a common disease like Hodgkin lymphoma was considered by us as worth highlighting. Among the Vinca alkaloids, peripheral neuropathy is the principal toxicity of Vincristine and neutropenia of Vinblastine, Vinorelbine, and Vindesine. Vinblastine neuropathy is rare and mild; whereas, Vinorelbine and Vindesine can be associated with moderate neuropathy. We were unable to find any guidelines on how to modify treatment in the event of such severe neurotoxicity. ${ }^{[3]}$ Most experts we consulted also denied having seen such severe neurotoxicity warranting change of treatment. To our knowledge there are no first line treatments approved in Hodgkin lymphoma which do not contain Vinca alkaloids. ${ }^{[4,5]}$ We managed our patient with two cycles of a second line regimen (ICE) as consolidation and till date (15 months post treatment) is in remission.

Pandalanghat Suresh, Rajan Kapoor, B. N. Kapur

Departments of Hematology and Medical Oncology, Malignant Diseases Treatment Centre, Command Hospital (SC),

Pune - 4 I I 040, Maharashtra, India

Correspondence to: Dr. Pandalaghat Suresh, E-mail:psuresh_n@yahoo.com

\section{References}

1. Hausheer FH. Chemotherapy-Induced peripheral neuropathy. In: Perry MC, editor. The Chemotherapy Source Book. $4^{\text {th }}$ ed. Philadelphia: Lippincott Williams and Wilkins; 2008. p. 234-42.

2. Hausheer FH, Schilsky RL, Bain S, Berghorn EJ, Lieberman F. Diagnosis, management, and evaluation of chemotherapy-induced peripheral neuropathy. Semin Oncol 2006;33:15-49.

3. Eric KR. Antimicrotubule agents. In: Chabner BA, editor. Cancer Chemotherapy and Biotherapy: Principles and Practices. $4^{\text {th }}$ ed. Philadelphia: Lippincott Williams and Wilkins; 2006. p. 241-2.

4. Eichenauer DA, Engert A, Dreyling M, ESMO Guidelines Working Group. Hodgkin's lymphoma: ESMO Clinical Practice Guidelines for diagnosis, treatment and follow-up. Ann Oncology 2011;22:vi55-8.

5. Hoppe RT, Advani RH, Ai WZ, Ambinder RF, Aoun P, Bello CM, et al. National Comprehensive Cancer Network. Hodgkin lymphoma, version 2.2012. 